\title{
Efficient Market Hypotheses of Nepalese Stock Market
}

\author{
Shanker Dhodary, MPhil \\ Lecturer, Nepal Commerce Campus, TU
}

\begin{abstract}
The purpose of this paper is to examine the random walk hypothesis (RWH) by testing the weak-form efficiency in the Nepalese capital market. Descriptive, correlation and causal comparative research design has been used for analyzing the variables and different phenomenon. This research has been prepared only with the help of secondary data. Closing price of company has been collected and analyzed for the period 2015/16-2019/20. Thus researcher tried to analyze the market efficiency with the help of five years data (daily closingprice).There are altogether around 233 companies listed in NEPSE. So to make this research feasible and simple researcher has selected only 10 companies from the NEPSE by using purposive sampling technique. In course of selecting company researcher has tried to incorporate only financial sectors as commercial banks, finance companies, insurance, and microfinance companies but development bank has not been taken as sample due to same nature of commercial bank. Researcher examined the weak form efficiency of the Nepal stock exchange (NEPSE) using auto correlation test (parametric test) and run test (non-parametric test) for the period of 2015/16-2019/20. Mainly this research work tested the efficient market hypothesis of Nepalese stock market with the help of daily closing price of 10 Sample Company of different sectors. The market is inefficient in the weak form implies that the NEPSE does not follow a random walk. This means that the NEPSE provides an opportunity for out- performance by skillful managers and investment specialists. Auto correlation exists in price of stock evident that there is high level of dependency of price of stock with the previous ones. It will be easy for speculator and trader to exploit the market and gain handsome profit from the market. All investor are not assumed to be rational in inefficient market, most of the people say investor are investing on the basis of market rumor. Market may be inefficient due the asymmetric of information and insider trading.
\end{abstract}

Key words: Efficient Market, Random walk, Weakform, Market rumor, Asymmetric information.

\section{Background of the Study}

In general terms, the ideal is a market in which price provide accurate signals for resource allocation: that is, a market in which firms can make production-investment decisions, and investors can choose among the securities that represent ownership of firms' activities under the assumption that security prices at any time "fully reflect" all available information. A market in which prices always "fully reflect" available information is called "efficient" (Fama, 1970). In efficient capital market all the investor are assumed rational so there is no chance of gaining abnormal profit from the market. All the investors are rewarded 
only normal rate of return i.e. market rate of return. No one investor can beat the market in efficient kind of market. The basic of the efficient market hypothesis is that the market consists of many rational investors who are constantly reading the news and respond quickly to any significant information about asecurity. The efficient markets hypothesis (EMH) assumes that profiting from predicting price movements is very difficult and unlikely. The main engine behind price changes is the arrival of new events information. A market is said to be "efficient" if prices adjust quickly and, on average, without bias, to new information. As a result, the current prices of securities reflect all available information at any given point in time. Consequently, there is no reason to believe that prices are too high or too low. Security prices adjust before an investor has time to trade on and profit from a new a piece ofinformation.

Market efficiency hypothesis to be the simple statement that security prices fully reflect all available information. A precondition for this strong version of the hypothesis is that information and trading costs, the costs of getting prices to reflect information, are always (Grossman \&Stiglitz, 1980). A weaker and economically more sensible version of the efficiency hypothesis says that prices reflect information to the point where the marginal benefits of acting on information (the profits to be made) do not exceed the marginal costs (Jensen, 1978). The ability of a stock market to perform its role efficiently is highly contingent to the extent on which it can be deemed efficient. The hypothesis demonstrating the efficiency of capital markets is grounded upon the realization that competitive behavior existing among profit-seeking participants will ensure that asset prices continuously adjust to reflect all price-influential information (Jawadi et.al 2009).

An efficient market is one where shares are always correctly priced. In an efficient capital market, current market prices fully reflect available information. Therefore, if the market is efficient, it uses all information available for setting a price. Market efficiency, as reflected by the Efficient Market Hypothesis (EMH), may exist at three levels - the weak form, the semi- strong form and the strong form which are briefly discussed below. The weak form of EMH states that the current share prices fully reflect all information contained in the past price movements. If this level of efficiency holds, there is no value in trying to predict future price movements by analyzing trend in past price movements by using fundamental and technical analysis. Therefore, the weak form of EMH argues that the trend offers no clues as to tomorrow's price - the stock market has no memory. The stock prices will fluctuate more or less randomly, any departure from randomness being too expensive to determine. Market called efficient in weak-form because it processes the information speedily, so prices cannot be predicted by the investors, so technical analysis for this phenomenon does not work for investors. In weak form, no investor can trounce the market by using past price movement because in weak form prices adjust according to the past information as it is reflected speedily in adjusting prices of stocks. In simple words that past prices of stocks have no correlation with today's stock price. The stock price movements will not follow any pattern; this is known as randomwalk. The semi-strong form of the EMH states that the current market prices reflect not only all past price movements, but also past all publicly available information. Stockprices adjust as the public information reflect immediately, as the event occurs, prices get adjusted accordingly There is no benefit in analyzing existing information, such as that given in published accounts, after the information has been released; the stock market has already captured this information in the current share price. So in this form, investor cannot predict the return by using publicly information .Only those with the access to information prior to its general release can earn superior or abnormal returns over the normal return expected for the associated degree ofrisk.

\section{Statement of the Problem}

There were several researches and empirical conducted for analyzing the level and degree of market efficiency. Most of the investor used chart and fundamental analysis for their investment purpose having a misconception with efficient market hypothesis. They believe that EMH says a stock's price correctly predicts the underlying company's future results. Since stock prices clearly do not reflect company future results in many cases, many people reject EMH as clearly wrong. (Fama 1991; Hawawini, 1994; and Lo, 
1997) argued that weak form of efficiency can be found in developing countries. The efficient market cannot be seen in less developed and emerging countries. Emerging markets such as China is not empirically efficient, that the Shanghai and Shenzhen markets, exhibit considerable serial correlation (price trends), non-random walk, and evidence of manipulation (Malkiel, 2007. The knowledge regarding the efficient market hypothesis is very important for individual investor for investment purpose similarly, it is equally worthy for government and regulatory body for preparation of rules, regulations and guidelines. Investor will try to identify miss priced securities and trade those until they reach in equilibrium prices.

\section{Hypothesis}

The purpose of this paper is to examine the random walk hypothesis (RWH) by testing the weakform efficiency in the Nepalese capital market. Therefore, the hypothesis to be tested:

H0: Nepalese Stock Market prices follow random walk, thus weak-form efficient.

H1: Nepalese Stock Market prices do not follow random walk, thus weak-form inefficient.

\section{Conceptual Framework}

Most of the investor has a confusion regarding the term and meaning of efficient market hypothesis. They believe that in efficient capital market, investor can predict the price of share in future days. But efficient market hypothesis state that price has no memory and it cannot be estimated in proper way. With the help of past data and with the use of chart and fundamental analysis no one can beat the market. Thus in efficient capital market all investor will get same level ofreturn.In this research project, to test the market efficiency in Nepalese capital market, researcher used the daily stock price of 10 companies for 5 years. In this research work stock price is taken as a dependent variable and lag of stock price, and change in stock price are taken as independent variable. There are different statistical tools available for examining market efficiency but researcher has only used auto correlation test and runtest.

The theoretical foundations for the efficient market hypothesis rest on the following three arguments, when all condition exist in the market at such situation the market is said to be efficient. In an efficient market all investor are assumed to have full information about the market and they will only get normal rate of return. There will be no probability of selecting mispriced security in this kind of market.

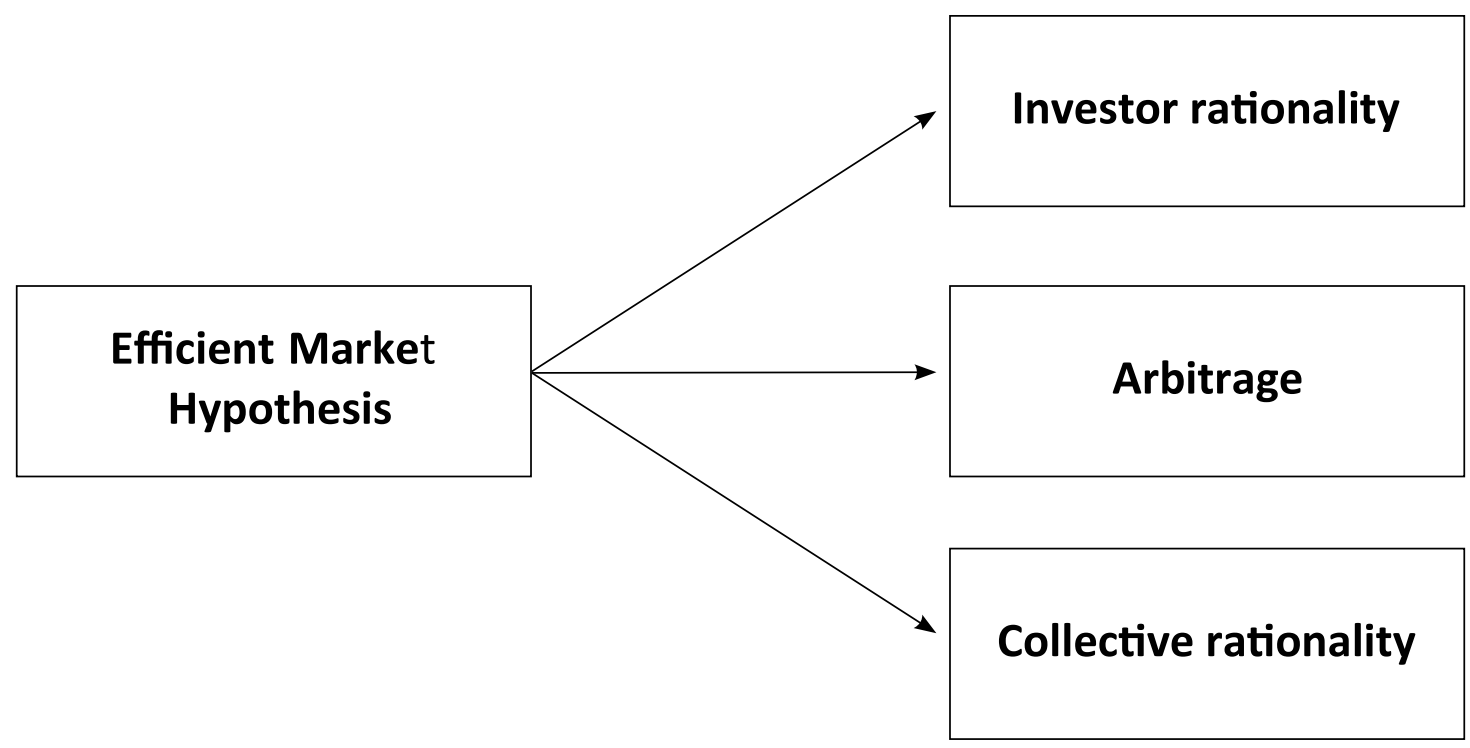

Fig: 2.1 Model of Efficient Market Hypothesis 
Issue 1 May/June 2020 -

\section{Definitions of variables}

i. Investor rationality: Investors are assumed to be rational, which means that they correctly update their beliefs when new information is available. All investor have full information about the market and economic condition of Nepal.

ii. Arbitrage: Even if not all investors are rational, some rational investors use arbitragetorem ovepricingerrors,sotheaverageinvestorwouldnotmatte the marginal investor sets prices. There will be no arbitrage opportunity in an efficient market. There is not a chance of picking mispriced securities.

iii. Collective rationality: The random errors of investors cancel out in the market. Some investors are not rational, they trade randomly and, consequently, their trades cancel each other without affecting the prices (Pesaran,2005).

\section{Review of Related Articles}

In 1953, Maurice Kendall, a British statistician, presented a controversial paper to the Royal Statistical Society on the behavior of stock and commodity prices. He examined the behavior of weekly changes in 19 indices of British industrial share prices and in spot prices for cotton (New York) and wheat (Chicago) with expectation to find regular price cycles but to his surprise they did not seem to exist. After extensive analysis of autocorrelations: "The series looks like a wandering one, almost as if once a week the Demon of Chance drew a random number from a symmetrical population of fixed dispersion and added it to the current price to determine the next week's price." The near-zero autocorrelation of price changes was an observation that appeared inconsistent with the views of economists. Kendall's conclusion had in fact been suggested earlier by (Working, 1934), though his suggestion lacked the force provided by Kendall's empirical results. Nevertheless, these empirical observations that the prices wander randomly poses a major challenge to market analysts who try to predict the future path of securityprices.

The mixed random walk model is a variant suggested by (Cootner, 1962). He divides market operators into two classes, amateurs and experts. The amateurs are relatively poorly informed about market conditions. However, other factors such as shifts in income distribution and income levels among shareholders with different evaluations of riskiness still tend to affect their actions randomly. In the short run these amateurs will produce a random walk in prices, possibly by the mechanism suggested in the pure random walk model. The classes of experts are, by contrast, far more knowledgeable. They will enter the market only when the random walk produced by the amateurs takes the price sufficiently far from what they consider to be the correct market price so as to compensate them for the opportunity cost involved in these market operations. In the long run, the sounder views of the experts will prevail, and produce a randomwalk.

Fama(1965), after being convinced with reviews and own tests, states that the price changes are independent and that therefore the past history of stock prices cannot be used to make meaningful predictions concerning its future behavior. Moreover,ifsomedependenceisfound,thenFamaarguesthatitistoosmalltobe profitably exploited because of transaction costs. In this study, (Fama, 1965) provides a solid foundation of empirical tests for theoretical base of random walk hypothesis; however, it was not until the work of (Samuelson, 1965) and (Mandelbrot, 1966) that the relationship between empirical models and the theory of random walk hypothesis were rigorously studied.

Ferson\& Harvey (1991) formally tested the common expected returns hypothesis. Using the asset-pricing models of (Merton, 1973) and (Ross, 1976), they try to link the time-series variation in expected returns, captured by dividend yields and term- structurevariables, tothecommonfactorsinreturnsthatdeterminethecross-section of expected returns. They estimate that the common variation in expected returns is about $80 \%$ of the predictable time-series variation in the returns on Government bonds, corporate bonds, and common-stock portfolios formed on industry and size. They can't reject the hypothesis that all the time-series variation in expected returns is common. More precisely, this theory contends that successive price changes are independent and prices at any time, on the average, reflect the intrinsic value 
of security (Fischer \& Jordan, 2000).

Regarding the stock price behavior of emerging stock markets, (Harvey, 1994) articulates that equity returns of emerging markets are highly predictable and have low correlations with equity returns of developed markets. Harvey, therefore, concludes that emerging equity markets are less efficient than developed markets and higher returns and lower risk can be obtained by incorporating emerging equities in investors' portfolio. (Khaba, 1998) has examined the behavior of stock prices in the financialmarketofSaudiArabiaandfoundthatthemarketwasnotefficientinits weak form. He explained that the inefficiency might be due to delay in operations and high transaction costs, thinness of trading and illiquidity in the market.

Osei (2002) investigated the asset pricing characteristics and response to annual earnings announcement of the Ghana Stock market and concluded that Ghana Stock Market is not efficient with respect to annual earnings information releases to the Ghanian Market.

Madhumita (2006) investigated the stock price behavior using daily closing figures of Milanka Price Index during January 1991 to December 2001 and daily closing prices of twenty-five underlying individuals companies included in the index from July 1991 to May1999. The study found that stock market in Sri Lanka did not follow random walk, while results of weak form efficient market hypothesis in twenty-five companies showed mixed outcome. (Daniel \& Samuel, 2006) examined the weak form of efficient market hypothesis for four Africanstockmarkets-Ghana,Mauritius,EgyptandSouthAfrica.

Theirresults implied that South African market was weak form efficient, whereas that of Ghana, Mauritius and Egypt were weak form inefficient.

On the other hand, a few studies showed some evidence of efficiency among the Arab stock markets.

A study by (Dahel \& Labbas, 1999) examined the Saudi Arabia, Bahrain, Oman and Kuwait stock markets for efficiency using auto- correlation, variance ratio and run tests. Their results suggested that these markets were efficient in the weak-form as the random walk hypothesis could not be rejected. In addition, (Abraham et. al 2002) examined three major GCC stock markets, Saudi, Kuwait and Bahrain, using variance ratio and runs tests. The initial results indicated a rejection to the random walk hypotheses in all three markets. However, after taking into consideration possible infrequent trading, they applied a correction to the index using (Beveridge \& Nelson, 1981) decomposition index returns. As a result, they failed to reject the random walk hypotheses in Saudi and Bahrain stock markets, whereas it was rejected in the Kuwaiti market.

Vaidyanathan \& Gali (1994) also found that the Indian capital market is weak form efficient using a filter rules test. (Mall, Pradhan, \& Mishra, 2011) use daily data from June 2000 to May 2011 and found that the Indian capital market is weak form efficient.

Harper \& Jin (2011) conducted autocorrelation and runs test to analyze daily index returns of the Bombay Stock Exchange from July 1997 to December 2011. The results of the autocorrelation and runs test indicate that the Indian stock market is not efficient in the weak form during their testing period and imply that it is possible to achieve abnormal returns by predicting the future price movements based on past stock pricemovements.

Haque (2013) empirically tested out the emerging market of Pakistan from (2000-2010) by analyzing the KSE- 100 weekly share index. Run test KPSS test were applied to get the result to test efficiency of stock market of Pakistan. After applying these tests, he concluded that autocorrelation results rejected the random walk behavior so KSE is weak form efficient. Unit root test after the application in data involved, it proposed that there is randomness in weekly share index data so that it demonstrated that Karachi stock exchange is not efficient market in weak form. From this, he had brought to closes that investors would earn abnormal profit after predicting future prices in inefficientmarket.

Asab (2015) conducted a research study for enquiring the weak-form market efficiency of Islamabad Stock Exchange in Pakistan. The main objective of this study is to test that whether it follows random walk or not. This study analyzes the daily closing index of ISE-10 from period Jan 1, 2013 to Dec 31, 
2013. It also reveals that no excess profits can be earned through using technical analysis. Many statistical techniques were applied to check the data normality and randomness and their dependence through various concerned tests. Run test and auto correlation test show market inefficiency at specific periods but ADF test descriptive showed market efficiency in weak form. ISE-10 showed market. So investors cannot predict market for gaining abnormal returns because market has dual nature and cannot be easily predictable to beat market so, it shows Islamabad Stock exchange is in weak efficient.

\section{Review of Nepalese Studies}

Baral and Shrestha (2006) observed the daily stock prices of sampled banks indicate that there is large variation in their stock prices in the fiscal year 2005/06. They are not doing well in Nepalese stock market. Most of the serial coefficients are significantly deviated from zero and statistically insignificant. It signifies that the successive price changes are dependent. Therefore, the Nepalese stock market is inefficient in pricing the shares. Runs test results also show that the percentage of deviation between the observed and actual number of runs in the series of price changes is significant. It is obvious that the successive price changes are not random. Thus, RWH does not hold true in the context of Nepalese stock market.

Niraula (2007) concluded from his study that the Nepalese stock market is not efficient either in weak form or in semi-strong form. The study revealed that the stock prices are not random and future prices can be estimated by analyzingthehistorical information. Further, price prediction is also possible by analyzing the news and thus the market can be exploited with the help of technical analysis and fundamental analysis. The notion clearly provided the evidence of market inefficiency.

The analysis of stock market efficiency has been done by (Bhatta, 2010) using the daily, weekly and monthly stock market returns. Applying the autocorrelation test and runs test author found that Nepali stock market does not show any sign of weak efficiency and returns follow no random walkprocess.

Gurung (2010) examines the weak form market efficiency of Nepalese stock market by using 1970 daily observations from 2003 to 2009 of the general NEPSE index and seven different sector-wise indices. The study employs five different tests of random walk such as autocorrelation test, runs test, unit root tests (ADF, PP, and KPSS), variance ratio test and autoregressive conditional and heteroskedasticity test. The results of the tests are in broad agreement, conclusively rejecting the presence of random walk in daily returns of the eight stock market indices. The serial correlation tests and the runs tests both revealed that the successive price changes are not random and are serially dependent. Similarly, the unit root tests conclude that unit roots, as necessary conditions for a random walk, are absent from all of the return series. Finally, the results of variance ratio and GARCH $(1,1)$ procedures convincingly reject the presence of random walks in the index returns series implying that the Nepalese stock market is not efficient in the weak form. In this way his study has also provided evidence against efficient markethypothesis.

Pandeya(2103) observed from secondary data analysis did not provide any strong evidence in favor of weak-form of market efficiency. Since auto-correlation analysis gave the contradictory results regarding the random walk behavior of stock prices of some of the less frequently traded individual companies, no generalizable conclusion can be derived about the existence of weak-form efficiency in Nepalese stock market because the runs test results contradicted the consistent result for those some of the less frequently traded stocks.

\section{Research Methodology}

Descriptive design has been used for analyzing the variables and different phenomenon and it helps to analyze the efficiency of market. Similarly, correlation design has been used to analyze the relationship between stock prices in different period of time. Casual comparative design is used to analyze whether it is possible to predict the future price based on historicalprices. This research project has been prepared only with the help of secondary data. Regarding secondary data the closing stock prices of different company has been extracted from their annual report, website and also from SEBON and NEPSE. Mainly data have 
collected from website of NEPSE. Closing price of company has been collected and analyzed for the period 2015/16-2019/20. Thus researcher tried to analyze the market efficiency with the help of five years data (daily closingprice).

There are altogether around 233 companies listed in NEPSE. So to make this research feasible and simple researcher has selected only 10 companies from the NEPSE by using purposive sampling technique. In course of selecting company researcher has tried to incorporateonly financial sectors as commercial banks, finance companies, insurance, and microfinance companies but development bank has not been taken as sample due to same nature of commercial bank.

Table 1

Lists of Sample Company

\begin{tabular}{llll}
\hline S.N. & Name of the Sample Firms & Study Period & Observations \\
\hline 1. & Agricultural Development bankLtd & $2015 / 16-2019 / 20$ & 5 \\
2. & Nepal Bank Ltd. & $2015 / 16-2019 / 20$ & 5 \\
3. & Nabil Bank Ltd. & $2015 / 16-2019 / 20$ & 5 \\
4. & ICFC finance Ltd & $2015 / 16-2019 / 20$ & 5 \\
5. & HAMA Finance Ltd & $2015 / 16-2019 / 20$ & 5 \\
6. & Nepal Life Insurance CompanyLtd & $2015 / 16-2019 / 20$ & 5 \\
7. & Prime Life Insurance CompanyLtd & $2015 / 16-2019 / 20$ & 5 \\
8. & Everest Insurance Company Ltd & $2015 / 16-2019 / 20$ & 5 \\
9. & RMDC & $2015 / 16-2019 / 20$ & 5 \\
10. & NirdhanUtthan Bank ltd & $2015 / 16-2019 / 20$ & 5 \\
\hline
\end{tabular}

\section{Analysis of Efficient Market Hypothesis by Serial Correlation Test}

Serial correlation is the relationship between a given variable and itself over various time intervals. Serial correlations are often found in repeating patterns, when the level of a variable affects its future level. In finance, this correlation is used by technical analysts to determine how well the past price of a security predicts the future price. If a variable's serial correlation is measured to be zero, then it means there is no correlation, and each of the observations is independent of one another. Conversely, if a variable's serial correlation skews toward one, it means that the observations are serially correlated, and that future observations are affected by past values. Essentially, a variable that is serially correlated has a pattern and isn'trandom.

\section{Commercial Banks}

If the calculated P-value is higher than 0.05 then there exists of weak form market efficiency implying that the price series is stationary. Selected sample commercial banks of Nepal's evident that there exists high level of positive auto-correlation in daily closing price of stock and p-value of almost them are 0.000 in the 20 lags. While examining the autocorrelations, relationship up to maximum LBL (99.1\%) and minimum NBL (65.8\%) have been seen, which shows there is high dependency of stock price with the previous ones. Thus the significant autocorrelations (Q-statistic) of commercial bank in Nepal rejected the null hypothesis supporting an evidence to reject the efficient market efficiency on the basis of serial correlation test.

\section{Finance Companies}

If the calculated P-value is higher than 0.05 then there exists of weak form market efficiency implying that the price series is stationary. Selected sample finance companies of Nepal's evident that there exists high level of positive auto-correlation in daily closing price of stock and p-value of almost them are 0.000 in the 20 lags. While examining the autocorrelations, relationship up to maximum PFC (99.3\%) and minimum 
HAMA and ICFC (51.3\%) have been seen, which shows there is high dependency of stock price with the previous ones. Thus the significant autocorrelations (Q-statistic) of finance companies rejected the null hypothesis supporting an evidence to reject the efficient market hypothesis in Nepal on the basis of serial correlation test. The details of calculation have been shown in Annex 3.

\section{Microfinance}

Selected sample microfinance of Nepal's evident that there exists high levelofpositiveauto-correl ationindailyclosingpriceofstockandp-valueofalmost them are 0.000 in the 20 lags. While examining the autocorrelations, relationship up to maximum FMDBL (99.0\%) and minimum RMDC (47.6\%) have been seen, which shows there is high dependency of stock price with the previous ones. Thus the significant autocorrelations (Q-statistic) of microfinance rejected the null hypothesis supporting an evidence to reject the efficient market hypothesis in Nepal on the basis of serial correlation test. The details of calculation have been shown in Annex4.

\section{Insurance Companies}

Selected sample Insurance companies of Nepal's evident that there exists high level of positive autocorrelation in daily closing price of stock and p-value of almost them are 0.000 in the 20 lags. While examining the autocorrelations, relationship up to maximum PLIC (99.2\%) and minimum HGI (62.8\%) have been seen, which shows there is high dependency of stock price with the previous ones. Thus the significant autocorrelations (Q-statistic) of insurance companies rejected the null hypothesis supporting an evidence to reject efficient market hypothesis in Nepal on the basis of serial correlation test.

\section{Analysis of Market Efficiency by RunTest}

Run test is a non-parametric test which converts the total number of runs into z-statistics. For large samples, 'z' will be approximately normally distributed with mean zero and variance one. Thus, the standardized normal variable $z$-test is used for testing significance. The z-statistics gives the probability of difference between the actual and expected number of runs. The z-value greater than or equal to $\pm \mathbf{1}$. 96 rejects the null hypothesis at 5 percent level of significance (Sharma \& Kennedy, 1977). Here researcher have tested and presented the sample company with the help of run test are as follows.

\section{Run Test of Commercial Banks}

The results of the run tests of commercial banks of Nepal show the negative value of Z-Statistics which proves that the null hypothesis of independence and randomness in stock price changes is rejected since the calculated Z-statistic of ADBL (-32.542), NBL (-23.908), NABIL (-32.164), SCB (-30.708), LBL $(-30.472)$ and

GBIME (-27.090) lies outside the critical values of \pm 1.96 at $5 \%$ significance levels. The negative $Z$-Statistic value indicates the actual number of runs is far less than the expected number of runs .A negative $\mathrm{Z}$ value also indicates the presence of positive serial correlations with respect to the return series. As mentioned in the methodology section, a significant Z-statistic is indicative of non-randomness and serial dependence in a return series. Therefore it can be concluded that the random walk and weak-form efficiency hypothesis is rejected for the Nepalese stock market in case of commercialbanks.

\section{Run test of Finance Companies}

The results of the run tests of finance companies of Nepal show the negative value of Z-Statistics which proves that the null hypothesis of independence and randomness in stock price changes is rejected since the calculated Z-statistic of HAMA(-21.210),PFC(-15.583),ICFC(-27.698), andJFL(-25.309)liesoutsidethe critical values of \pm 1.96 at $5 \%$ significance levels. The negative Z-Statistic value indicates the actual number 
of runs is far less than the expected number of runs.A negative $\mathrm{Z}$ value also indicates the presence of positive serial correlations with respect to the return series. As mentioned in the methodology section, a significant Z-statistic isindicativeofnon-randomnessandserialdependenceinareturnseries. Thereforeit can be concluded that the random walk and weak-form efficiency hypothesis is rejected for the Nepalese stock market in case of finance companies.

\section{Run Test of Microfinance}

The results of the run tests of microfinance of Nepal show the negative value of Z-Statistics which proves that the null hypothesis of independence and randomness in stock price changes is rejected since the calculated Z-statistic of DDBL (-25.969), RMDC (-18.351), NUBL (-22.660), and FMDBL (-20.244) lies outside the critical values of \pm 1.96 at $5 \%$ significance levels. The negative Z-Statistic value indicates the actual number of runs is far less than the expected number of runs. A negative $Z$ value also indicates the presence of positive serial correlations with respect to the return series. As mentioned in the methodology section, a significant Z-statistic is indicative of non-randomness and serial dependence in a return series. Therefore it can be concluded that the random walk and weak-form efficiency hypothesis is rejected for the Nepalese stock market in case ofmicrofinance.

\section{Run Test of Insurance Companies}

The results of the run tests of development banks of Nepal show the negative value of Z-Statistics which proves that the null hypothesis of independence and randomness in stock price changes is rejected since the calculated Z-statistic of NLIC (-30.053), PLIC (-31.483), EIC (-16.600), and HGI (-18.053) lies outside the critical values of \pm 1.96 at $5 \%$ significance levels. The negative Z-Statistic value indicates the actual number of runs is far less than the expected number of runs. A negative $Z$ value also indicates the presence of positive serial correlations with respect to the return series. As mentioned in the methodology section, a significant Z-statistic is indicative of non-randomness and serial dependence in a return series. Therefore it can be concluded that the random walk and weak-form efficiency hypothesis is rejected for the Nepalese stock market in case of insurance companies.

\section{Discussion}

From the above findings and presentation it can be concluded that Nepalese capital market is inefficient. Investor can beat the market with the help of fundamental and technical analysis. There exists auto-correlation and non-randomness in price of stock so there is high possibility of gaining abnormal return in Nepalese capital market. The result derived from this run test also consistent with the previous research work done in Nepalese context by (Aryal, 1995), (Shrestha, 1999), (Paudel, 2003), (Bajracharya, 2003), (Mainali, 2003), (Baral\& Shrestha, 2006), (Pradhan \&Upadhyay, 2006) and (Bhatta, 2010).

Thus from the above analysis it can be summarized that Nepalese stock market is not in efficient form. Investor can easily estimate the trend and pattern of price behavior of stock with the help of past data. While doing literature review it was found that market is found to be inefficient mostly in underdeveloped countries due to low level of economic activities, lack of financial awareness, less development of basic infrastructures for the promotion of stock market. Similarly development of capital market is depends on economic and political stability of anation.

Researcher has analyzed the Nepalese capital market considering daily closing price of stock for 2011 to 2015 with the help of Serial Correlation test and Run test. Researcher has also included Sample Company from all the sectors as commercial banks, development banks, finance companies, microfinance, insurance companies, trading sector, manufacturing sector, hotel sector, hydropower companies, mutual funds and other sectors but all of them rejected null hypothesis. The price movement of Nepalese stocks is not random and therefore, fundamental analysis can be used to beat the market. Thus, data analysis gives 
the results not in favor of weak-form of market efficiency. So on the basis of analysis it can be concluded that Nepalese capital market do not follow random walk. Nepalese capital market isinefficient.

\section{Conclusion}

Under this study effort has been made to examine the existence or non- existence of weak-form efficiency in Nepalese stock market. The empirical test has been done to determine whether the price of a stock in one period relates to its price in the following period or not. Efficient market hypothesis asserts that if the sequence of stock prices is random, future price movements cannot be predicted and the market can be exemplified as being efficient in its weak-form. In weak efficient market, the time series of stock prices move independently to their own past values. At such condition the price series are random in nature. This study intends to test whether the time series values of stock prices in Nepalese stock market are independent or dependent to eachother.

Researcher examined the weak form efficiency of the Nepal stock exchange (NEPSE) using auto correlation test (parametric test) and run test (non-parametric test) for the period of 2015/16-2019/20. Mainly this research work tested the efficient market hypothesis of Nepalese stock market with the help of daily closing price of 32 Sample Company of different sectors. Secondary data analysis has been done to observe the statistical properties of stock prices and to test whether they follow the characteristics of weakform market efficiency ornot.

The results from this study suggest that stock price changes on the NEPSE are not random and exploitable patterns exist, making it possible for arbitrage portfolios to be constructed based on trading rules. This observation contradicts the weak form of the EMH.

The results of the autocorrelation and runs test rejected the null hypothesis indicated that the Nepalese stock market is not efficient in the weak form during testing period and imply that it is possible to achieve abnormal returns by predicting the future price movements based on historical stock price movements. In efficient market all the investor benefitted only normal rate of return since any news and information instantly reflected in price of stock. There is no chance of selecting mispriced (buying undervalue security and selling overvalued security) security, since all the investor are rational and have a full information about stock price and market movement. In efficient kind of market no one investor can truly predict the price, only negligible \% of investor earn above market return due to their fortune. On contrary inefficient stock market like Nepal is a good place for investment since price has a pattern and can be estimated. Thus investor has a chance to beat and exploit the market only in inefficient market likeNepal.The market is inefficient in the weak form implies that the NEPSE does not follow a random walk. This means that the NEPSE provides an opportunity for out- performance by skillful managers and investment specialists. Auto correlation exists in price of stock evident that there is high level of dependency of price of stock with the previous ones. It will be easy for speculator and trader to exploit the market and gain handsome profit from the market. All investor are not assumed to be rational in inefficient market, most of the people say investor are investing on the basis of market rumor. Market may be inefficient due the asymmetric of information and insider trading.

\section{References}

Abraham, A., Seyyed, F., \&Alsakran, S. (2002). 'Testing the Random Walk Behavior and Efficiency of the Gulf Stock Markets'. The Financial Review, 37(3), 469- 480.

Asab, M. z. (2014, April). Testing the Weak Form Efficiency of Islamabad. Developing Country Studies, 4. Baral, K. J., \& Shrestha, S. K. (2006, dec). Daily Stock Price Behavior of Commercial Banks in Nepal. The Journal of Nepalese Business Studies, 3(1).

Bhatta, G. (2010). Does NepaliStock Market Follow Random Walk?SEBON Journal, 18- 58.

Brealey, R., Myers, S., \& Marcus, A. (1999). Fundamentals of Corporate Finance, 2nd.

Bulter, K., \&Malaikah. (1992). 'Efficiency and Inefficiency in Thinly Traded Stock Markets: Kuwait and 
Saudi Arabia'. Journal of Banking and Finance, 16, 197- 210.

Cooper, j. (1982).World Stock Markets: Some Random Walk Tests. Applied Economics.

Cootner, P. (1962). "Stock Prices: Random versus Systematic Changes. Industrial Management Review, $25-45$

Dahel, R., \&Laabas, B. (1999). 'The Behavior of Stock Prices in the GCC Markets'.

Economic Research Forum for the Arab Countries, Iran \&Turkey.Daniel, S., \& Samuel, 1. (2006).

The Efficiency of Selected African Stock Markets", Finance India,. 20(2), 553-571.

Fama, E. (1970). Efficient Capital Markets: A Review of Theory and Empirical Work. The Journal of Finance, 383-417.

Ferson, Wayne, E., \& Campbell, R. (1991). The variation of economic risk premiums. Journal of Political Economy, 385-415.

Fisher, Donald, E., \& Ronald, J. (2000). . Security Analysis and Portfolio Management. 12th Indian Reprint. New Delhi: Prentice Hall of India Pvt. Ltd.

Gujrati, D. (2004). Basic Econometrics, Tata McGraw-Hill Publishing Company Ltd. Gupta, R., \&Basu, P. (2007). Weak form efficiency in Indian stock markets. International Business and Economics Research Journal, 57-64.

Harvery, C. (1994).Conditional Asset Allocation in Emerging Markets, Working Paper, No. 4623, Cambridge, M. A.

Jawadi, F., Burneau, K., \&Sghaier, N. (2009).Nonlinear Cointegration Relations betweenNon-Life Insurance Premiums and FinancialMarkets. The Journal of Risk and Insurance,753-783.

Jensen, M. (1978). Some Anomalous Evidence Regarding Market Efficiency. Journal of Financial Economics, 95-101.

Khaba, N. (1998).Behavior of Stock Prices in the Saudi Arabian Financial Market: Empirical Research Findings, Journal of Financial Management and Analysis, 11(1), 48-55.

Lo, A., \&Mackinlay, A. (1988).Stock market prices do not follow random walks:Evidence from a simple specification test",. The Review of Financial Studies, 41-46.

Madhumita, C. (2006). On validity of Random Walk Hypothesis in Colombo Stock Exchange, Sri Lamka. Decision, 33(1), 135-161.

Mandelbrot, B. (1966).Forecast of Future Prices, Unbiased Markets, and Martingale Models. Journal of Business, 242-255.

Merton, R. C. (1973). An intertemporal capital asset pricing model. Econometrica, 867- 887.

Mishra, P. (2012). Efficiency of South Asian Capital Markets An Empirical Analysis. Pak. J. Commer. Soc.

Mobarek, A., \&Keasey, K. (2000). "Weak Form Market Efficiency of an Emerging Market: Evidence from Dhaka Stock Market of Bangladesh. Working Paper, Leeds University Business School.

Modigliani, F., \& Richard, B. (1955). Utility analysis and the consumption function, in K. Kurihara, Ed., Post Keynesian Economics, (G. Allen, London).

Niraula, U. K. (2007). Stock Market Efficiency: A Case of Nepal. (M. Phil dissertation, Tribhuvan University, 2007).

Nisar, S., \&Hanif, M. (2012).TestingWeak-Form of EfficientMarket Hypothesis: Empirical Evidence fromSouth-Asia. 'WorldApplied Sciences Journal, 414-427.

Ojah, K., \&Karemera, D. (1999). 'Random Walk and Market Efficiency Tests of Latin American Emerging Equity Markets: A Revisit'. The Financial Review, 34(2), 57-72.

Osei. (2002).Asset Pricing and Information Efficiency of the Ghanaian StockMarket. AERC Research Paper 115, Nairobi, Kenya.

Pandeya, C. (2013).Efficient market hypothesis and behaviour of share prices: The Nepalese Evidence. (M. Phil dissertation, Tribhuvan University, 2013).

Pant, B., \&Bishnoi, T. (2001). Testing random walk hypothesis for Indian stock market indices. Proceedings of the Fifth capital markets conference.UTI Institute of Capital Markets. 
Pesaran, M. (2005). Market Efficiency Today. IEPR Working Paper [E- document]. Poshakwale, S. (1996). "Evidence on the Weak Form Efficiency and the Day-of-the-Week-Effect in the Indian Stock Market. Finance India, 10(3), 605-616.

Pradhan, R. S., \&Upadhyay, B. D. (2004). The Efficient Market Hypothesis and the Behavior of Share price in Nepal. The Nepalese management Review.

Roberts, H. (1967).Statistical versus Clinical Prediction of the Stock Market. Unpublished paper presented to the Seminar on the Analysis of Security Prices, University of Chicago.

Ross, S. A. (1976). The arbitrage theory of capital asset pricing.Journal of Economic Theory, 341-360.

Samuelson, P. (1965). Proof that properly anticipated prices fluctuate randomly. Industrial Management Review, 41-49.

Schweret, G. (2002).Anomalies and Market Efficiency.Working Paper, National Bureau of Economic Research, Cambridge.

Shrestha, M., \& Bhandari, D. B. (2004). Financial Markets and Institutions. Kathmandu: Asmita Publication.

Smith, G., \& Jefferis, K. (2002).The Evolving Efficiency of African Stock Markets. Unpublished Research Paper, School of Oriental and African Studies, University of London. 